\title{
CONFLITO DE GERAÇÕES NOS PROJETOS
}

\section{CONFLICT OF GENERATIONS IN PROJECTS}

Data do recebimento do artigo: 13/04/2013

Data do aceite do artigo: 16/09/2013

Data da publicação: 2/12/2013

\author{
Eliziane Jacqueline dos Santos Inácio Ferreira ${ }^{1}$ \\ Mestre em Psicologia \\ Doutoranda em Saúde Coletiva \\ Universidade Federal de São Paulo
}

Erica Mignoni Paiva

Graduado em Sistemas de Informação

Universidade Braz Cubas

Gregory Rodolfo Ferreira

Graduado em Tecnologia de Gestão de Internet e Redes de Computadores

Universidade Braz Cubas

Mauro Minoru Suzuki

Graduado em Administração

Universidade Braz Cubas

\section{RESUMO}

Este artigo compara as diferentes gerações de profissionais no mercado de trabalho, analisando suas características, os fatores motivadores e os conflitos entre essas gerações no que se refere à gestão de projetos. Utilizando da pesquisa teórica, verificou-se que a nova geração está chegando à liderança das empresas mais rápido do que as gerações anteriores e isso têm causado problemas de conflito nas equipes de projeto. Por essa razão, é necessário um gerenciamento adequado, para que as diferenças não atrapalhem, mas sim que contribuam para sucesso do projeto. Conclui-se sobre a importância de novas ferramentas e técnicas que os profissionais que gerenciam ou gerenciarão projetos, poderão utilizar para gerenciar esses diferentes profissionais, minimizando os conflitos da equipe e elevando a probabilidade de sucesso do projeto.

Palavras-chaves: Gestão de Projetos, Gerações, Conflito de Gerações.

\footnotetext{
${ }^{1}$ Autor para correspondência: Universidade Federal de São Paulo - Rua Botucatu, 740 - 50 andar. Vila Clementino, São Paulo, SP - Brasil. CEP: 04023-900.
} 


\begin{abstract}
This article compares different generations of professionals in the labor market, analyzing their characteristics, motivating factors and conflicts between these generations in relation to project management. Using the theoretical research, it was found that the new generation is coming to leadership companies faster than previous generations and this has caused problems of conflict in project teams. For this reason, you need a proper management, so that the differences do not hinder, but rather to contribute to project success. The results of this study suggest tools and techniques that professionals who manage or will manage projects, may use to manage these different professionals, minimizing conflicts team and raising the probability of project success.
\end{abstract}

Keywords: Project Management, Generations, Generational Conflict. 


\title{
1. INTRODUÇÃO
}

Os veteranos de projeto estão vivendo uma nova era com a enxurrada de jovens profissionais que estão chegando ao mercado que muitas vezes tem atitudes muito diferentes na maneira de se comunicar, colaborar e lidar com tarefas e isso está levando uma tensão aos projetos. Em muitos projetos é possível encontrar quatro gerações trabalhando na mesma equipe: Tradicionalistas, Baby Boomers, Geração X e a Geração Y. Neste contexto, o gerente de projeto deve considerar o que cada grupo necessita para ser bem sucedido, pois sem essa compreensão, as falhas de comunicação irão resultar em desalinhamentos que irão levar ao fracasso do projeto.

\subsection{AS GERAÇÕES E O MUNDO DO TRABALHO}

No Dicionário Aulete (2008, p. 1) a palavra geração significa:

\begin{abstract}
Conjunto de pessoas da mesma idade ou que nasceram no mesmo período histórico; Período de tempo (aproximadamente 25 anos) entre o nascimento de uma pessoa e o nascimento de seus filhos; Fase que marca uma mudança no comportamento humano.
\end{abstract}

Quando se escreve sobre gerações, é preciso considerar os diversos fatores que ajudam a entender o tema, principalmente o conceito que é mais aceito pelos estudiosos - a separação da sociedade pela idade cronológica. Não é muito simples identificar uma geração apenas pelo período de nascimento, já que existem outros fatores que interferem na formação de um ser humano, tais como cultura, família, educação, padrão econômico e localização. Ou seja, tem sido mais comum considerar a classificação geracional levando-se em conta os acontecimentos sociais e culturais coletivos, sobretudo os aspectos comportamentais mais fáceis de serem identificados.

Claro que, com um leque tão amplo e abstrato, é possível realizar especulações com diversos graus de profundidade, mas não é incorreto utilizar uma classificação que tenha como objetivo apontar diferenças comportamentais resultantes de períodos históricos com grandes movimentos sociais que interferiram e continuam interferindo na sociedade. (OLIVEIRA, 2012, p. 25).

A classificação geracional, segundo Oliveira é apresentada no quadro 1: 


\begin{tabular}{|l|l|l|l|l|}
\hline \multicolumn{1}{|c|}{ NOME } & \multicolumn{1}{|c|}{$\begin{array}{c}\text { PERÍODO } \\
\text { Nascidos nas } \\
\text { décadas }\end{array}$} & \multicolumn{1}{c|}{$\begin{array}{c}\text { Centro } \\
\text { da } \\
\text { geração }\end{array}$} & Característica & \multicolumn{1}{|c|}{$\begin{array}{c}\text { Principal } \\
\text { ansiedade }\end{array}$} \\
\hline Belle Époque & $1920 / 1930$ & 75 anos & $\begin{array}{c}\text { Idealistas } \\
\text { Sonhadores }\end{array}$ & Disciplina \\
\hline Baby Boomers & $1940 / 1950$ & 60 anos & $\begin{array}{c}\text { Estruturados } \\
\text { Construtores }\end{array}$ & Revolução \\
\hline Geração X & $1960 / 1970$ & 45 anos & $\begin{array}{c}\text { Céticos } \\
\text { Tolerantes }\end{array}$ & Facilidades \\
\hline Geração Y & $1980 / 1990$ & 22 anos & $\begin{array}{c}\text { Desestruturados } \\
\text { Contestadores }\end{array}$ & Inovações \\
\hline Geração Z & $2000 \ldots$ & 10 anos & $\begin{array}{c}\text { Conectados e } \\
\text { relacionais }\end{array}$ & Equilibrio? \\
\hline
\end{tabular}

QUADRO 1 CLASSIFICAÇÃO GERACIONAL FONTE: Oliveira ((2012, p. 26).

O quadro 1, portanto, demonstra a existência de cinco gerações convivendo na atualidade. Isso ocorreu porque nos últimos anos a expectativa de vida foi ampliada de forma significativa em todo o mundo, inclusive no Brasil. 


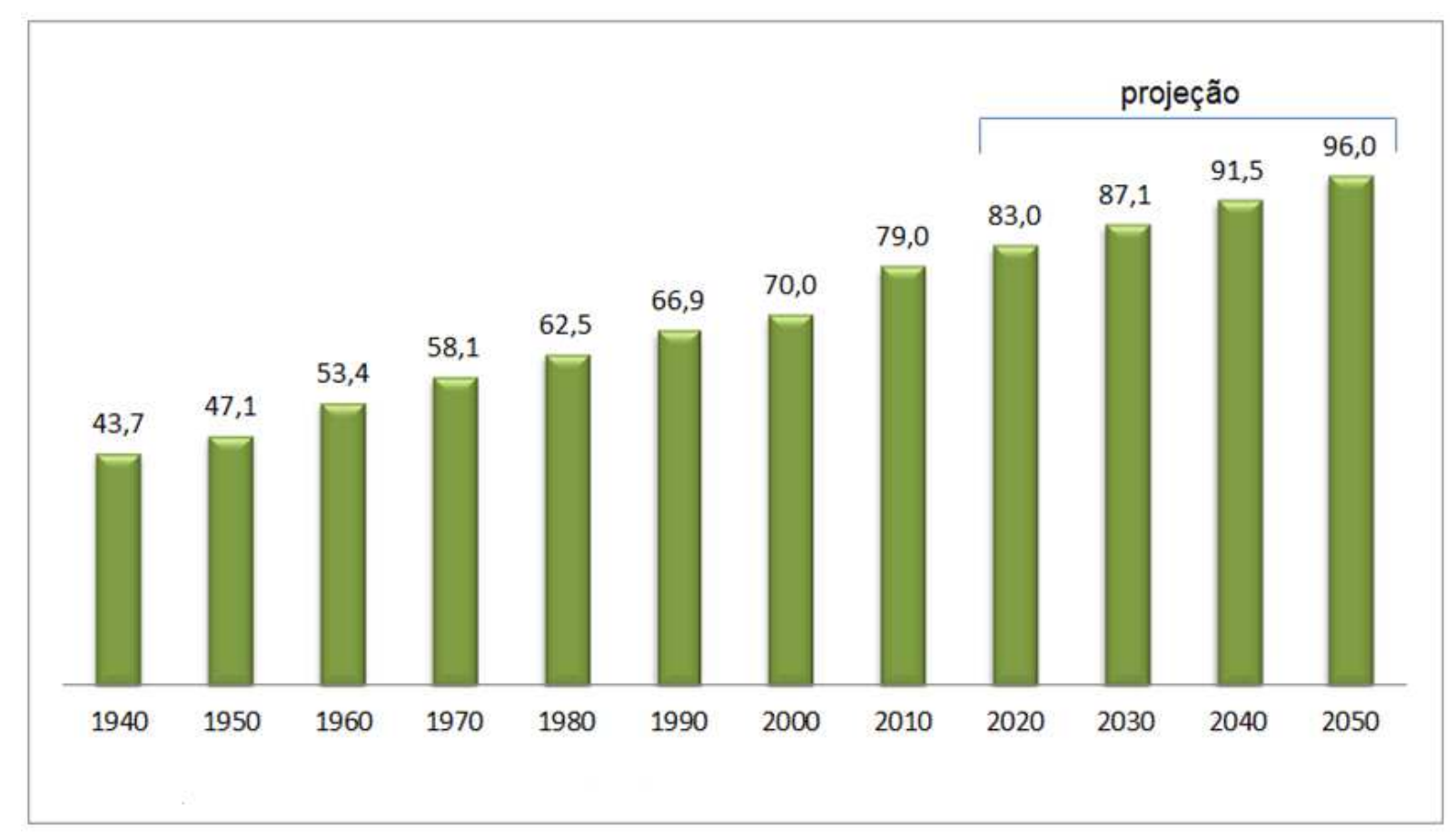

FIGURA 1 EXPECTATIVA DE VIDA (EM ANOS)

Fonte: IBGE, 2010.

\subsection{CLASSIFICAÇÃ̃O DAS GERAÇÕES}

O conceito de "gerações" pode ser descrito como conjunto de pessoas da mesma idade ou que nasceram no mesmo período histórico que marca uma mudança no comportamento humano e que causa um impacto direto na evolução da sociedade.

Para compreender as gerações é necessário saber em qual período histórico essa geração cresceu e quais são as características comportamentais mais nítidas em cada uma dessas gerações.

Tradicionalistas: Essa geração foi criada num ambiente de incerteza no período das grandes crises econômicas e viveram a época da $2^{\mathrm{a}}$ Guerra Mundial.

Os tradicionalistas eram dedicados, cultuavam uma perspectiva essencialmente prática e mantinham profundo respeito diante da autoridade. A liderança se dava por hierarquia e dentro dela reinava um imenso espírito de sacrifício (MENDES, 2009). Para Eline Kullock (2010, p. 1), especialista em gerações, os tradicionalistas são pessoas mais rígidas e respeitam regras, por causa das dificuldades que viveram. 
Baby Boomers: Dessa geração fazem parte às pessoas nascidas logo após a $2^{\mathrm{a}}$ Guerra Mundial, quando o índice de natalidade cresceu incrivelmente, por isso o termo "baby boomer". Essa geração foi educada para competir, trazida com muita disciplina, ordem e respeito pelo outros. Essas qualidades não foram consideradas ou apreciadas nos anos seguintes, como aponta CONGER apud SANTOS (2011, p. 1). Diante da rigidez da disciplina que recebiam a tendência natural à rebeldia aparecia na música, momento que surge o Rock and Roll e grandes nomes da música como Elvis Presley, Bob Dylan, Beatles e Rolling Stones (OLIVEIRA apud SANTOS, 2011).

Os Baby Boomers mantinham uma perspectiva otimista e uma profunda ética profissional, porém a postura diante da autoridade era uma relação de amor e ódio. A liderança se dava por consenso e apresentava um grande espírito de automotivação, apesar das incertezas. Esse conceito não é tão amplo para nós brasileiros quanto é para os americanos, japoneses, ingleses e alemães, entre outros, que viveram o período difícil, antes e depois da $2^{\mathrm{a}}$ Guerra Mundial (MENDES, 2009). Para essa geração a empresa vem em primeiro lugar e a realização profissional está atrelada a empregos duradouros, as pessoas estão acostumadas a trabalhar em equipe, acredita no poder da hierarquia e seguem à risca as políticas corporativas (RECINELLA, 2010).

Os Baby Boomers viveram na época da globalização, da ida do homem à lua, do capitalismo e do consumismo. Cultuaram o Rock and Roll, o movimento Hippie, a contestação política e social e os movimentos pela paz. Viveram também a guerra do Vietnã, a ideologia libertária e o feminismo, entre muitos outros movimentos que mudaram a sociedade. Tais fatores explicam muito sobre o modo de pensar dessa geração, que é contestadora e lutou muito por seus direitos (KULLOCK, 2010).

Geração X: Essa geração testemunhou na família o impacto de perder o emprego no qual se planejara ficar a vida inteira, passaram a repudiar o estilo "viver para trabalhar" e começaram a valorizar a vida pessoal. Foi essa a geração da Paz e Amor e do Festival Woodstock (RECINELLA, 2010).

As inovações tecnológicas avançaram significativamente deixando grandes marcas na juventude da época, favorecendo a aceleração das atividades diárias, promovendo 
manifestações revolucionárias e qualificando estilos diferenciados nos modos de viver desses jovens (LOMBARDIA apud SANTOS, 2011).

A Geração X, apesar de possuir uma ética profissional equilibrada, é a que mantém uma perspectiva cética e uma postura desinteressada diante da autoridade. Para os profissionais da Geração X, a liderança é fruto da competência e pesa sobre eles um espírito de descompromisso diante da realidade. Atualmente, a Geração X ainda domina a hierarquia na maioria das organizações. Trata-se de uma geração que também é fruto do "Mito da Tecnologia e da Modernidade", a qual, diferente das gerações anteriores, teve acesso a novos mercados, a novas línguas e a tecnologia após a década de 1980 (MENDES, 2009).

Kullock (2010, p. 1), afirma que essa geração entrou em um novo mundo fora das perspectivas utópicas, tendo que se conformar com um padrão de vida mais realista e consumista em pleno período de Guerra Fria.

Geração Y: Essa geração se beneficiou de um período economicamente favorecido e viveu em casa a liberdade que nenhuma outra geração teve. (KULLOCK, 2010). As pessoas desse período são consideradas ambiciosas, individualistas, instáveis, todavia, preocupadas com o meio ambiente e com os direitos humanos. Também são identificadas como esperançosas, decididas, coletivas e com um bom nível de formação, geralmente agindo sem autorização e desenvolvendo um alto poder e/ou pretensão de consumo. Tendem a fazer várias coisas ao mesmo tempo, gostam de variedade, desafios e oportunidades. Outra característica marcante das pessoas da Geração Y é que aceita a diversidade, convive muito bem com as diferenças de etnia, sexo, religião e nacionalidades em seus círculos de relação (LOIOLA apud SANTOS, 2011).

Geração Z: O que define uma geração é um determinado modelo mental. Se o modelo mental não muda, não há como identificar uma nova geração chegando ao mercado. Ainda não é possível detectar ou visualizar um modelo mental diferente entre os jovens de 15 a 20 e entre os de 20 e 25 . Portanto, não se pode dizer que os " $Z$ " sejam uma nova geração que entrará no mercado de trabalho. Essa é uma continuação da Geração Y. Talvez, em alguns anos, vejamos uma tendência maior, em função das mudanças climáticas, para um modelo mental que valorize e respeite mais as questões ambientais, que não é o foco da Geração Y. Porém, isso seria antecipar o futuro, que é uma coisa muito difícil (KULLOCK, 2010). 


\section{POR QUE SURGEM OS CONFLITOS DE GERAÇÕES?}

De acordo com a Antropologia: "uma cultura é a forma de vida de um grupo de pessoas, segundo comportamentos aprendidos e transmitidos de geração em geração por meio da língua falada e da simples imitação" (CORTUCCI, 2012, p. 1).

Ocorre que os mais experientes, os Tradicionalistas, os Baby Boomers e a Geração X, foram treinados de uma forma diferente. Por terem vivenciado tempos turbulentos sentem-se receosos diante de mudanças radicais, sejam elas de visão, sejam elas de comportamento. Nas décadas de 90 e, principalmente, a de 80, gerenciar um grupo de pessoas com grande capacidade de se comunicar, além de muita confiança para tomar decisões e ainda com facilidade para interagir com parceiros no mundo todo, definitivamente, era um grande e verdadeiro desafio (CORTUCCI, 2012).

Por outro lado, os mais jovens, a Geração Y e a Geração Z, com a tecnologia advinda da internet e recentemente pelas redes sociais, estabeleceu a mais rápida cultura que se tem registro, assim como a mais significativa geração até então registrada. Neste período da eclosão arrebatadora da internet, os jovens têm a facilidade de incorporar tecnologia em seu dia a dia, a capacidade de realizar múltiplas tarefas, a impaciência para carreiras profissionais lineares, a aversão à rotina, a preocupação com a qualidade de vida, a busca por uma rápida ascensão financeira, a defesa de causas sociais e a liberdade de criação.

Eles são frequentemente caracterizados por um grande entusiasmo em estabelecer uma rede de contatos e pela facilidade de trabalhar de forma colaborativa. Além de entusiasmados e otimistas, têm um forte desejo de aprenderem para se desenvolverem como força de trabalho.

Por essas razões, a Geração Y está chegando ao topo tão rápido que hoje começa a liderar profissionais que entraram no mercado de trabalho antes dela, ou seja, lideram pessoas da Geração X, os Baby Boomers e em alguns casos os Tradicionalistas. Com isso, as áreas de RH começam a enfrentar o problema de conflito entre as gerações (MENDONÇA apud AGUILAR, 2011). 
Segundo Bork (2012, p. 1): "O sofrimento nasce no momento em que insistimos ser uma linha reta num caminho repleto de curvas". Em outras palavras, os conflitos entre as gerações surgem, pois estamos vivendo uma mudança radical nas organizações, e se os gestores mais experientes não se adaptarem aos novos tempos, usando para isso sensibilidade para administrar a mudança comportamental das equipes de projetos, os resultados poderão levar essa relação com os jovens profissionais a um impasse (CORTUCCI, 2012).

\subsection{A VALORIZAÇÃO DAS DIFERENÇAS NA GESTÃo DE PROJETOS}

Embora os lideres de projetos devem evitar estereótipos, existem claras diferenças entre as gerações a serem abordadas. Eles devem aproveitar todas as diferenças de gerações através de um ajuste consciente das metodologias, tecnologias e diferentes estilos.

O gerente de projeto deve fazer com que a equipe do projeto aproveite as diferenças, tanto de gerações, como culturais, em clima de confiança mútua, pois assim, a equipe do projeto melhora as habilidades das pessoas, as competências técnicas, o ambiente global da equipe e o desempenho do projeto (PMBOK, 2008).

Os jovens líderes de projetos precisam lutar para serem levados a sério por seus superiores e devem colocar mais esforços para firmarem-se com sua equipe.

As características positivas dos líderes da Geração Y em relação às outras gerações são:

- A ganância em correr atrás dos resultados: Esses líderes incorporam a velocidade de executar com a de decisão, por isso podemos afirmar que a liderança do individuo da Geração Y é ágil e prática, visando eficiência e eficácia no resultado de suas atitudes e ações (AGULIAR, 2011).

- Possuem uma autoestima invejável, pois buscam incansavelmente por mais desafios, confiando sempre em seu potencial, assim seus representantes não expressam medo em situações de disputa de poder e autoridade.

- A colocação das funções na organização de forma hierárquica é repudiada pelos líderes da Geração Y, por acreditarem que a convivência em rede e em 
caráter informal é mais eficaz, pois aproximam os integrantes do grupo e/ou equipe.

- A afinidade com a tecnologia e sua forte influencia pela mesma, faz com que a Geração $Y$ esteja um passo a frente das demais gerações, pois a necessidade tecnológica das empresas é clara, e quem não possui o mínimo de conhecimento ou disposição para adequar-se a ela, "não está escalado para a seleção de profissionais do futuro" (BOOG apud AGUILAR, 2011).

As características negativas dos líderes da Geração Y em relação às outras gerações são:

- A Geração Y não está acostumada a enfrentar grandes adversidades, visto que estão acostumados a apertar um botão no computador e resolver tudo. Por estarem habituados com resultados rápidos e eficazes, terão que aprender a tirar o pé do acelerador. Por isso, a Geração Y deve se inspirar na disciplina dos mais velhos, visto que eles trabalharam em uma época com menos recursos e tiveram que batalhar bastante para obter resultados. Além disso, precisarão ter calma, e apesar das adversidades, terão que aprender a manter o foco.

- A Geração Y não tem lealdade para as empresas que trabalham se comparada com as gerações anteriores, que são profissionais que "vestem a camisa" da organização a que "servem", pois considera um dever da profissão ser fiel a empresa que trabalham (AGUILAR, 2012).

- São inexperientes nas relações humanas, por isso acham mais fácil mudar o rumo do que lidar com as dificuldades de relacionamento que lhes forem impostas. Por essa razão, a Geração Y precisa de supervisão e orientação equilibrada, que não lhes afete a criatividade (MARCON apud ANTUNES apud AGUILAR, 2012).

\section{METODOLOGIA DE PESQUISA}

A metodologia utilizada conforme objetivo do trabalho foi a pesquisa exploratória, através de pesquisas bibliográficas em artigos e reportagens sobre as gerações e seus conflitos nos projetos. A pesquisa bibliográfica tida como forma de gerir um processo sistemático de 
construção e/ou ampliação de conhecimento teve como foco a discussão das diferenças nas gerações Tradicionalistas, Baby Boomers, X, Y e Z. A análise dos dados encontrados foi de natureza descritiva, usando o método comparativo. A partir do método comparativo, podemse perceber as diferentes transformações, construir modelos e tipologias, identificando continuidade e descontinuidades, semelhanças e diferenças, além de explicitar as determinações tidas como genéricas na ocorrência de fenômenos sociais, tal como apontam Schneider e Schimitt (1998).

\section{RESULTADOS DA PESQUISA}

O foco da pesquisa foi identificar os tipos de geração e seus comportamentos, além de compreender como ocorrem os conflitos nos projetos e qual a melhor forma de gerenciá-los. Para atender essa problemática, buscou-se demonstrar o que é cada geração, bem como descrever as características de cada geração, incluindo a gestão de conflitos nos projetos.

$\mathrm{Na}$ análise dos textos escolhidos, verificou-se que o caminho para gerenciar os conflitos entre as gerações e tirar proveito das diferenças é a convivência, estabelecendo novas relações hierárquicas - e parcerias - que permitam explorar ao máximo as potencialidades dessa experiência entre gerações. Entre as iniciativas que os gerentes de projetos podem promover para enfrentar o problema destacam-se programas de conscientização e capacitação dos profissionais acerca do que cada realidade tem a oferecer (CALDEIRA, 2011). Também é importante a criação de programas de integração. Mostrar para os mais velhos, as novas ferramentas tecnológicas, que como exemplo facilitam a comunicação e a interação da equipe, entre outros benefícios. Por outro lado, os mais jovens precisam se dispor a aprender com a velha guarda, lições como: A importância das velhas e boas relações interpessoais, a falta que faz um bom planejamento, ter uma visão de processo, coisa que os jovens têm deficiência, e de comunicação cara a cara.

Também é necessário intermediar negociações entre as partes, fomentando o senso crítico de cada um com relação a si próprio e ao outro. Quando o gerenciamento é adequado, as diferenças de opinião podem resultar em aumento de criatividade e melhoria no processo decisório (PMBOK, 2008). Com essa mistura entre as gerações, ajudará a equipe do projeto a compreenderem que cada geração tem competências diferentes. 
Uma ferramenta eficaz que ajuda neste processo é o mentoring ${ }^{2}$. No caso dos jovens, é necessário ajudá-los em sua "síndrome do recém-formado", visto que essa geração ainda está em formação e algumas vezes desorientados. Não se deve "abandonar" essa geração numa relação exclusiva com sua chefia direta, sob o peso da hierarquia (CALDEIRA, 2011).

As ações do mentoring permitem ao indivíduo o autoconhecimento e a oportunidade de conhecer o outro, abrindo a possibilidade de um diálogo mais estruturado entre as partes, e de também sensibilizar a equipe de projetos para a necessidade de preparo para lidar com esses novos profissionais.

Para as gerações mais experientes, vale buscar a convivência com os subordinados, tentando conhecer a realidade e os interesses dessa geração jovem, onde os próprios gerentes de projetos podem ajudá-los a construí-las. (CALDEIRA, 2011).

Os lideres da Geração Y, devem ter em mente que trabalham com pessoas idealistas e empenhadas que prezam pela sua empresa e preocupam-se com questões sociais e ambientais. Também leva em consideração a responsabilidade individual, liberdade de expressão e precisam de flexibilidade de tempo e espaço. Para motivá-los, é importante que a comunicação seja clara e objetiva, as recompensas devem ser atingíveis, nada de metas em longo prazo. Eles esperam que você pratique tudo que prega, seja coerente com seus discursos e cumpra as devidas promessas, do contrário, buscarão novos métodos e outras empresas para desfrutarem de novas experiências (MARCON apud ANTUNES apud AGUILAR, 2011).

\section{CONCLUSÃO}

O conflito de gerações entre profissionais sempre existiu e sempre existirá. No entanto, o novo nunca cedeu menos que o velho, pois sabemos que o que virá sempre se sobreporá ao que está. A melhor maneira de transpor a barreira entre as diferentes gerações, durante a condução dos projetos, é estimular a troca de experiências mútua, definir regras claras para comunicação, e também definir regras claras para a autonomia que o gerente de projeto terá sobre a equipe (GALE, 2012). É necessário também que o gerente de projeto,

\footnotetext{
${ }^{2}$ Mentoring: É um método de processo de transposição de conhecimento, realizado com a ajuda de um mentor - profissional que irá estimular o desenvolvimento de um profissional em início de carreira, cargo ou novo em uma determinada corporação.
} 
avalie os membros da equipe e verifique em quais etapas, certos tipos de personalidades e geração, se destacam em relação a outras, oferecendo também, recompensas, feedback, treinamentos adicionais e ações disciplinares. Agindo dessa forma, o gerente de projeto construirá um ambiente saudável, unido e focado no resultado final, que é a entrega do projeto de acordo com Escopo, Prazo, Custo e métricas de Qualidade estipuladas.

\section{REFERÊNCIAS}

AGUILAR, Camila S., LIMA, Washington L. C.,PIMENTEL, Andréia A., SACAGNI, Sonia R., SANTOS, Maria F.: Geração Y e os desafios da liderança; Disponível em: http://fgh.escoladenegocios.info/revistaalumni/artigos/edEspecialMaio2012/Geracao_Y_e_os _Desafios_da_Lideranca.pdf. Acesso em 17/09/2012.

BORK, Marla; Todo o meu amor pelas cores!; 2012; Disponível em http://todoomeuamorpelascores.blogspot.com.br/2012/06/o-sofrimento-nasce-no-momentoem-que.html; Acessado em 28/10/2012.

CALDEIRA, Júlio; Como administrar conflitos de gerações; 2011; Disponível em http://www.canalrh.com.br/Mundos/saibacomo_artigo.asp?o=\%7B3B58C102-CA9D-43969B56-36CF232FB97B\%7D; Acessado em 28/10/2012.

CORTUCCI, Dalton; O conflito de gerações é uma oportunidade para a "Geração Y"; 2012; Disponível em http://www.administradores.com.br/informe-se/artigos/o-conflito-de-geracoese-uma-oportunidade-para-a-geracao-y/64973/; Acessado em 28/10/2012.

DICIONÁRIO AULETE; Geração; 2008; Disponível em http://aulete.uol.com.br/geração; Acessado em 28/10/2012.

GALE, Sarah Fister; Bridging the great divide; PM Network; Abril 2012.

GUIA PMBOK, $4^{\mathrm{a}}$ Edição, 2008. Pennsylvania, EUA: Project Management Institute, Inc.

KULLOCK, Eline; Foco em Gerações; 2012; Disponível em http://www.focoemgeracoes.com.br/; Acessado em 28/10/2012.

- Por que as gerações estão no nosso foco?; 2010; Disponível em http://www.focoemgeracoes.com.br/index.php/por-que-as-geracoes-estao-no-nosso-foco/; Acessado em 28/10/2012.

- Quem são os veteranos?; 2010; Disponível em http://www.focoemgeracoes.com.br/index.php/quem-sao-os-veteranos/; Acessado em 28/10/2012. 
Você conhece os baby boomers?; 2010; Disponível em http://www.focoemgeracoes.com.br/index.php/voce-conhece-os-baby-boomers/; Acessado em 28/10/2012.

O que é Geração X?; 2010; Disponível em http://www.focoemgeracoes.com.br/index.php/quem-faz-parte-da-geracao-x/; Acessado em $28 / 10 / 2012$.

- O que é Geração Y?; 2010; Disponível em http://www.focoemgeracoes.com.br/index.php/afinal-o-que-e-geracao-y/; Acessado em 28/10/2012.

- 2010; O que é Geração Z?; 2010; Disponível em http://www.focoemgeracoes.com.br/index.php/o-que-e-geracao-z/; Acessado em 28/10/2012.

. O conflito de gerações é uma oportunidade para a "Geração Y”; 2010; Disponível em http://www.focoemgeracoes.com.br/index.php/2012/08/01/o-conflito-de-geracoes-e-umaoportunidade-para-a-geracao-y/; Acessado em 28/10/2012.

LANCASTER, Lynne C.; STILlMAN, David. O Y da Questão. São Paulo: Saraiva, $2010 / 2011$.

MENDES, Jerônimo; Conflito de Gerações; 2009; Disponível em http://www.administradores.com.br/informe-se/artigos/conflito-de-geracoes/31473/; Acessado em $28 / 10 / 2012$.

OLIVEIRA, Sidnei. Jovens Para Sempre. São Paulo: Integrare, 2012.

RECINELLA, Roberto; Conflito de Gerações; 2010; Disponível em http://www.administradores.com.br/informe-se/artigos/conflito-de-geracoes/47532/; Acessado em $28 / 10 / 2012$.

SANTOS, Cristiane F. ARIENTE, Marina, DINIZ, Marcos V. C., DOVIGO, Aline A.; O processo evolutivo entre as gerações $\mathrm{X}, \mathrm{Y}$ e Baby Boomers; Disponível em http://www.ead.fea.usp.br/semead/14semead/resultado/trabalhosPDF/221.pdf; Acessado em 22/10/2012.

SCHNEIDER, Sergio; SCHIMITT, Cláudia Job. O uso do método comparativo nas Ciências Sociais. Cadernos de Sociologia, Porto Alegre, v. 9, p. 49-87, 1998. 